\title{
A dança como política do encontro com pessoas e lugares ${ }^{\star}$
}

\author{
Ruth Torralba Ribeiro, ${ }^{I \star \star}$ Lidia Costa Larangeira, "Laura Vainer de Albuquerque, ${ }^{I I I}$ \\ Bruna Raquel Simões Gouvêa, ${ }^{I I}$ Thaís Leitão Chilinque ${ }^{I I}$ \\ ${ }^{I}$ Faculdade Angel Vianna, Rio de Janeiro, RJ, Brasil \\ ${ }^{I I}$ Universidade Federal do Rio de Janeiro, Rio de Janeiro, RJ, Brasil \\ III Universidade Federal Fluminense, Niterói, RJ, Brasil
}

\begin{abstract}
Resumo
Este relato de pesquisa visa partilhar a experiência no projeto "Cartografias do Corpo na Cidade", realizado pelo Núcleo de Pesquisa, Estudos e Encontros em Dança da Universidade Federal do Rio de Janeiro (UFRJ). O Núcleo utiliza a cartografia como bússola metodológica para mapear experiências intensivas na cidade em que a dimensão vibrátil dos corpos é acionada. Neste artigo destacamos os processos de errância e ocupação afetiva na região portuária do Rio de Janeiro e a realização de proposições de dança em movimentos de resistência política no ano de 2016, como prática artística de re-existência. Ao investigar a fricção entre arte-e-vida, expandimos o entendimento do que pode a dança quando emerge do encontro com pessoas e lugares.
\end{abstract}

Palavras-chave: dança; cidade; política.

\section{Dance as a meeting policy with people and places}

\begin{abstract}
This research report aims to share the experience in the project "Cartographies of the body in the city", conducted by Núcleo de Pesquisa, Estudos e Encontros em Dança of the Federal University of Rio de Janeiro (UFRJ). Núcleo uses cartography as a methodological compass to map intensive experiences in the city in which the vibrating dimension of the bodies is triggered. In this article, we highlighted the experience in the processes of wandering and affective occupation in the port region of Rio de Janeiro and the realization of dance propositions in political resistance movements in the year 2016 as a re-existence artistic practice. By investigating the friction between art and life, we expand the understanding of what can dance do when it emerges from the encountering with people and places.
\end{abstract}

Keywords: dance; city; policy.

Este texto apresenta algumas experiências de re-existência políticas do corpo na cidade a partir do projeto de pesquisa "Cartografias do corpo na cidade", do Núcleo de Pesquisa, Estudos e Encontros em Dança, do Departamento de Arte Corporal da UFRJ. A pesquisa se interessa pelo encontro com pessoas e lugares para refletir e criar práticas de corpo e cidade. A perspectiva em dança na qual nos inserimos acontece na fricção entre arte-e-vida como uma composição entre corpo, movimento, cidade, escrita, imagem, som e processos de subjetivação. Orbitamos ao redor da zona portuária do Rio de Janeiro - região que sofreu recorrentes intervenções urbanísticas ao longo de sua história, particularmente nos anos de 2011 a 2016, com o Projeto Porto Maravilha - e nos mantemos próximos aos acontecimentos político-culturais da cidade, alargando, inclusive, os contornos da Universidade.

A atuação do Núcleo aposta na ocupação afetiva e artística de espaços como procedimento para a produção de conhecimento em dança. Trata-se de uma dança expandida que produz percepções, reflexões e fazeres que questionam e re-localizam nossos processos de formação e criação em dança. Neste sentido, traremos as forças de investigação teórico-práticas do Núcleo para criar, nesta escrita, três planos de composição ou de con-

\footnotetext{
^Fonte de financiamento: Programa de Bolsas de Iniciação Artística e CulturalPIBIAC/UFRJ 2016

$\star \star$ Endereço para correspondência: Faculdade Angel Vianna. Rua Jornalista Orlando Dantas, 2 - Botafogo. Rio de Janeiro - RJ. Brasil. CEP: 22231-010 E-mail:ruthtorralba@gmail.com, llarangeira@yahoo.com.br, laauravainer@ gmail.com, brunarsgouvea@gmail.com, thais.thaischilinque@gmail.com
}

sistência ${ }^{1}$ que identificamos como zonas intensivas em nossa pesquisa. O primeiro plano é chamado "errarcom, estarcom”, sua introdução é feita por uma cartografia que reflete a construção da pesquisa a partir da errância e do encontro. O segundo, "a cartografia como bússola", aborda como o método da cartografia pode ativar, pela via da experiência, a pesquisa artístico-acadêmica em dança. O terceiro plano intitulado "proposições coletivas como experiência de re-existência nas ocupações da cidade do Rio de Janeiro" apresenta parte de nossa atuação em mobilizações políticas populares ocorridas em 2016.

Os planos de composição têm deslizamentos entre si, por isso a narrativa deste artigo compromete-se menos com a ordem cronológica dos acontecimentos e mais com a co-emergência das linhas de força que desenham cada plano. Interessado nos atravessamentos que emergem na experiência, o processo de escrita implica-se em ser, ele próprio, uma composição das forças que movem a pesquisa. Realizamos arranjos de palavras, rodopios; posicionamos ideias, conceitos, referências, para que o texto seja, pela ordenação de caracteres, espaços, letras e palavras, um material de reflexão em dança. Escrever tem sido uma aventura..., como dançar uma dança..., como surfar uma onda: todo o corpo presente, todos os poros como olhos, ouvidos e tônus.

"A metodologia de escrita deste texto é inspirada no artigo "Planos de Composição" de André Lepecki (2012). 


\section{1: errarcom, estarcom}

sobre segunda feira, todas as segundas no Morro

segunda-feira é dia de encontro. me Alegro, e mais do que isso, me Admiro que toda a segunda-feira a gente continue enfrentando todas as adversidades da vida, continue resistindo e indo... indo, se encontrando e se abrindo para o encontro. mesmo sem obrigação, mesmo sem cobrança, mesmo sem verba, sem bolsa, sem garantia.

mesmo que às vezes alguém não venha, alguém adoeça, alguém não consiga chegar, alguém tenha uma banca, um congresso, um trabalho, um filho doente, existe um 'nós' que sempre arrisca não estar lá, mas que sempre chega. é a junção desse nós que garante que esse mesmo nós continue a existir. e isso é Admirável, e mais do que isso, Espantoso.

então, toda segunda-feira nos reunimos na Casa Porto e conversamos sobre coisas: vida, projetos, fatos, autores... e saímos para a rua sem rota previamente estabelecida. sem nenhuma ação previamente combinada. nos une a experiência coletiva de uma atenção aberta à espreita de um encontro com as pessoas e lugares (o que a Ruth chama de atenção felina) olhamos sem foco para que as coisas nos olhem de volta, chamem o nosso olho, nada. deriva. uma porosidade na atenção, na escuta e na presença. chamando por uma "dança" que esteja emaranhada na nossa caminhada, nas nossas lentes de contato, na sola do sapato que toca nosso pé no chão. uma dança invisível. percebo que não distinguo mais roupa de dança e roupa de vida. me Surpreendo, e mais do que isso, me Delicio.

aos poucos, com a persistência da nossa presença, com a continuidade do nosso nós, toda segunda-feira, começamos a criar cúmplices...o francisco da Casa Porto, dona maria da casa 8, os meninos da "boca", a escola, a igreja, as flores do jardim, o gato preto, as pedras da rua do escorrega, o olho d'água que brota no meio do concreto, a escadaria que não aparece no mapa, a dona da casa que cuida das flores, o adro, o mezanino, a sombra da árvore, os espaços de nada. tudo gente-tudo coisa. vou mapeando esses encontros com meu celular na mão, capturando imagens que são uma tentativa de atualizar a experiência de olhar para algo que me toca. me Entusiasmo, e mais do que isso, sinto Vertigem quando me encontro com esses pequenos detalhes que me vibram a presença. todas as camadas de tempo e vida grudadas nas paredes, nas pedras, nas portas, nas janelas. o que fazer com isso? volta e meia caímos no buraco de ter que fazer algo que conste no hall de tarefas previamente estabelecidas. estamos criando a não tarefa de juntar-nos para nada, forçar o espaço do nada, ocupar-nos do nada, violar a ordem produtivista, violentar a urgência de ser especialista em coisas, de estar no circuito instituido e reconhecido... estamos criando um circuito por dia. chupar sacolé, conhecer o observatório, deitar na rua, entregar uma flor, criar correspondências, escrever, fotografar, andar com sapato de dança, desenhar, conversar, olhar, visitar, imaginar. gestos para nada, dança, obrigada Deligny!
Me Assombro, e mais do que isso, me Maravilhocom, todas as segundas-feiras, no morro. ${ }^{2}$

O Núcleo foi criado pela necessidade de aproximar artistas-pesquisadores interessados em investigar, a partir do encontro, perguntas comuns tais como: Por que dançar? Como dançar em ressonância com os acontecimentos políticos que se iniciaram em junho de $2013 ?^{3}$ Como articular as questões da nossa cidade com a dança na Universidade? Como pode a dança ativar as questões políticas do território em que atuamos? Como pode a dança, em sua dimensão de encontro, ser uma experiência de re-existência?

Sem um objeto de pesquisa, um tema ou uma hipótese previamente estabelecidos, o ponto de convergência do grupo foi a necessidade de fabular, divagar e exercitar as questões comuns. Nesse contexto a errância urbana, ${ }^{4}$ como uma experiência participativa na cidade, revelou-se como metodologia que possibilita orbitar em torno de nossas inquietações e descobrir-inventar procedimentos formativos e criativos na pesquisa em dança. Tendo a indeterminação, a imprevisibilidade e a incerteza como elementos presentes e desejados, a metodologia de trabalho em errância utiliza a intuição, a espreita e a abertura para escutar e acolher o que lá está como potência. Em nosso interesse por pesquisar possíveis cartografias do corpo na cidade, realizamos práticas de errância que incluem caminhadas, permanências, derivas, paragens e observações pelas ruas, escadarias, largos, praças, vielas, jardins, viadutos, esquinas e outras topografias habitadas por moradores de rua, brincantes, ambulantes, traficantes, artistas, skatistas, prostitutas e passantes.

O plano de composição "errarcom” consiste em uma prática de errância urbana coletiva que se lança sem rotas previamente estabelecidas, sem objetivo e sem metas, em ressonância com as pessoas e os lugares da cidade. Dedicamos tempo à experiência de abertura para o encontro, para investigar esse estado de presença que necessariamente é vulnerável, intensivo e vibrátil. Emergem, portanto, do "errarcom", algumas linhas de atuação do projeto, brevemente enunciadas a seguir:

1) Ocupação afetiva e ações artísticas nas ruas do Morro da Conceição, tendo a Casa Porto como parceiro institucional. Por exemplo: leituras e discussões nas praças, refeições compartilhadas nas ruas, exercícios de escrita em ressonância com os lugares, conversas com moradores e comerciantes, prova das comidas locais, visita a espaços culturais, realização de improvisações em dança, experimentação de programas performativos, etc.

\footnotetext{
${ }^{2}$ Este texto é uma cartografia construída em travessias realizadas no Morro da Conceição. Outras cartografias produzidas pelo núcleo podem ser encontradas em <http://nucleodeestudoseencontros.blogspot.com.br $>$.

${ }^{3}$ Nos referimos às manifestações populares que eclodiram em todo o território nacional, iniciadas pelo descontentamento com o aumento abusivo das tarifas de ônibus e contagiadas por outras insatisfações, tendo marcado a história do ano de 2013 e os movimentos de resistência até hoje.

${ }^{4}$ Paola Berenstein Jacques (2005), no texto "Errâncias urbanas: a arte de andar pela cidade", realiza um pequeno histórico das errâncias urbanas modernas dividindo em três: o Flâneur de Baudelaire de final do séc XIX, as deambulações aleatórias dos dadaístas e surrealistas de 1910-1930 e a deriva urbana dos situacionistas dos anos 1950 e 1960
} 


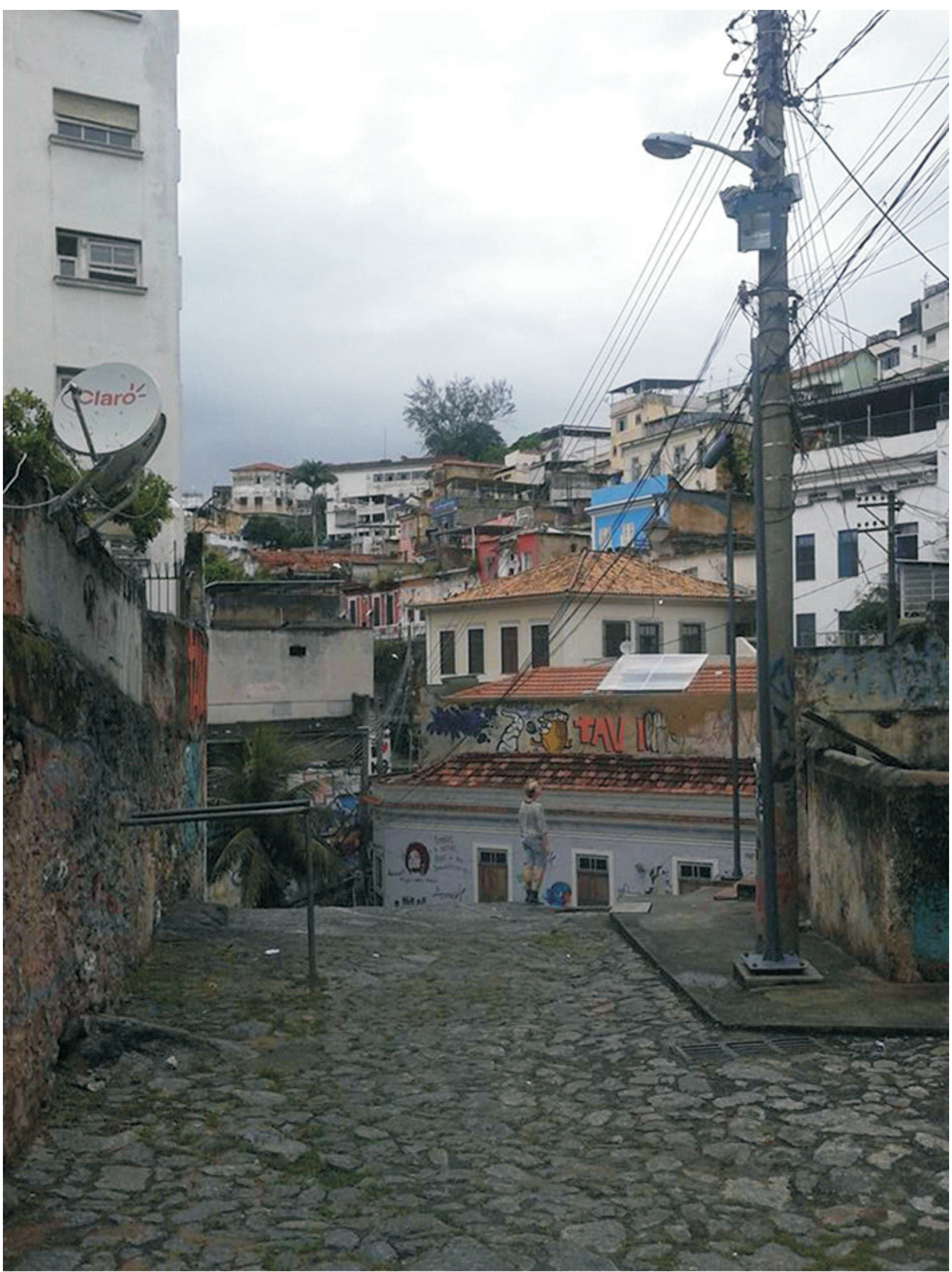

Figura 1 - Errância no Morro da Conceição - RJ

2) Proposições em mobilizações populares de ocupação na cidade do Rio de Janeiro (\#OcupaAmaro, \#OcupaMincRJ, \#OcupaSusRJ), tratadas no terceiro plano deste texto;
3) Ciclo de Encontros de Extensão, realizado na Casa Porto. Conversas demoradas com artistas, pesquisadores/as e profissionais que pensam arte e cidade em seus engendramentos políticos; 
4) Produção de materialidades artístico-acadêmicas: publicações no blog do grupo, trabalhos de conclusão de curso, trabalho cênico solo intitulado "Brinquedos para Esquecer";

5) Intercâmbio com festivais e participação em eventos de arte e pesquisa como: Pedras d'Água organizado pelo c.e.m - centro em movimento (Lisboa/PT), em julho de 2016; e World Dance Alliance - Americas, (Puebla/ MX), em agosto de 2016.

O c.e.m, instituição de investigação artística de Lisboa, lança em 2010 uma revista virtual chamada Pedras $d$ 'Água - A arte de estar com pessoas e lugares, na qual discute o termo "estarcom" utilizado na pesquisa. Observamos, estudando as publicações do c.e.m, que o termo aparece grafado de maneiras diferentes: estar com, estar-com e posteriormente estarcom e estarcom. É interessante notar o caminho que a palavra caminha para consolidar-se como um conceito que emerge de uma urgência, de uma necessidade. Nas palavras de Agostinho, gestora artística do c.e.m:

Detecto que as propostas que alimentamos no c.e.m têm muitas vezes essa característica: como não trabalhamos por objectivos mas por urgências, frequentemente organizamos palavras pela necessidade de nomear o indizível até que ele pela insistência da prática se transforma de facto em algo que pode ser dito e então vai ocupando o lugar do nome que lhe foi destinado [...] Pessoas e Lugares não fala de quem nem de onde, mas da experiência de Estar-Com. Também não fala de "O quê". Estar-Com para nós não denuncia a necessidade de um quê para onde deságua o Estar. Pessoas e Lugares não são por isso alvos a "estar com", mas sim potenciadores da relação que faz aparecer a particularidade da acção Estar-Com enquanto ela própria, sem necessidade de qualquer finalidade para se cumprir. É dessa atenção, desse espaço aberto que convida a fazer aparecer o que até aqui não tinha forma, que se reorganiza tudo o resto que já lá estava, da mesma forma evidente que colocar mais uma rosa num bouquet obriga a que todas as outras flores que já lá estavam se reposicionem. Não se trata portanto de uma obrigação filosófica ou moral mas de uma evidência física (AGOSTINHO, 2010, p. 3-4).

Por urgências que nascem do encontro e da errância, algumas palavras foram emergindo em nosso vocabulário - pensar com, compor com, criar com, desejar com, errarcom e estarcom: o sufixo "com" tonifica a contração coletiva e aponta para a potência dos movimentos que se constituem coletivamente. A experiência em errância pela cidade constituiu com muita densidade a noção de que a dança pode ser uma prática artística de re-existência, de ressignificação do corpo em seu território, reconfigurando relações desgastadas e exauridas pelos modos de produção de consumo e propondo experimentações que abrem outras subjetividades, corporeidades, novos e potentes territórios existenciais.

\section{2: A cartografia como bússola}

$\mathrm{Na}$ busca por encontrar-nos, coletivamente, com saberes e práticas menos delimitadas e estratificadas, o método da Cartografia é utilizado como instrumento para pensar-produzir pesquisa acadêmica em dança, por tratar-se de uma abordagem que entende a pesquisa como acompanhamento de processos, produção de subjetividade, criação de realidades e de mundos. O educador francês Fernand Deligny criou na França, na década de 1970, uma comunidade para acompanhar crianças autistas severamente comprometidas. Ele, juntamente com seus pares, desenvolveu um sistema cartográfico para entrar em "relação" com essas crianças através do mapeamento das linhas de errâncias desenhadas em seus trajetos cotidianos, acompanhando-as em suas derivas e aproximando-se delas pela partilha espacial dos gestos e não pela linguagem. Em 1980, Deleuze e Guattari (1996, p. 21) no livro Mil platôs apontam brevemente para o conceito de cartografia, a partir do trabalho de Deligny, pensando a construção do conhecimento como uma atitude rizomática e "inteiramente voltada para uma experimentação do real". Posteriormente, nos anos 1980, Guattari e Rolnik realizam exercícios cartográficos em viagens acompanhando movimentos micro e macropolíticos pelo Brasil. Dessas viagens os autores escrevem juntos o livro $\mathrm{Mi}$ cropolitica: cartografias do desejo (GUATTARI; ROLNIK, 1996) em 1986 e individualmente Suely Rolnik (1989) escreve Cartografia sentimental: transformações contemporâneas do desejo. Todas essas obras são referências para o desenvolvimento do nosso trabalho, sendo o livro Pistas do método da cartografia: pesquisa-intervenção e produção de subjetividade de 2009, organizado por Eduardo Passos, Virginia Kastrup e Liliana Escóssia a obra que tem orientado teoricamente a nossa produção. O referido livro é composto por oito pistas que vão desenhando a atuação do cartógrafo em seu processo de pesquisa-intervenção em diversas áreas do conhecimento.

A investigação pela via cartográfica desinveste em um modo de pesquisa que se ocupa em analisar um determinado objeto ou fenômeno de forma apartada da experiência do pesquisador. A relação sujeito-objeto na pesquisa a partir do método da cartografia é íntima, afetiva e de construção mútua. Segundo Barros e Passos (2009, p. 17):

A Cartografia como método de pesquisa-intervenção pressupõe uma orientação do trabalho do pesquisador que não se faz de modo prescritivo, por regras já prontas nem com objetivos previamente estabelecidos. No entanto, não se trata de uma ação sem direção, já que a cartografia reverte o sentido tradicional de método sem abrir mão da orientação do percurso da pesquisa. [...] O ponto de apoio é a experiência entendida como um saber-fazer, isto é, um saber que vem, que emerge do fazer. Tal primado da experiência direciona o trabalho da pesquisa do saber-fazer ao fazer-saber, do saber na experiência à experiência do saber. Eis aí o "caminho" metodológico.

A partir do paradigma do cartógrafo, entendemos que a pesquisa é sempre criação de realidades e subjetividades. Para Barros e Passos "conhecer o caminho de cons- 
tituição de dado objeto equivale a caminhar com esse objeto, constituir esse próprio caminho e constituir-se no caminho" (BARROS; PASSOS, 2009, p. 31).

Afirmando que o objeto de pesquisa se produz no processo de pesquisar, a cartografia torna-se uma ferramenta precisa para o trabalho que realizamos, ao acompanharmos, carne-a-carne, os referidos processos de re-existência na cidade. Rolnik (1989) ressalta que é tarefa do cartógrafo dar língua para os afetos que pedem passagem. Dele se espera que esteja mergulhado nas intensidades de seu tempo. Um dos procedimentos metodológicos adotados por nós é a atenção aberta e flutuante: uma atitude para estarmos em sintonia com as forças que nos atravessam, de modo a ativar a potência do corpo vibrátil. Para Rolnik (2010, online):

[...] o corpo vibrátil é aquele ponto de interrogação em nós que está sempre levando a uma recriação do espaço, ele é irredutível ao nosso contorno atual, é a presença do mundo no nosso corpo que nos leva a ser mundo e a criar mundo.

Nas práticas de errância que realizamos na cidade, exercitamos a atenção do cartógrafo e ficamos à espreita de um encontro: atitude que habita a duração do enquanto: presente. As cartografias são construídas na experiência afetiva com os espaços da cidade. Elas são desdobramentos escritos, fotográficos e videográficos das experimentações vividas em campo. Cartografar tem sido para nós uma experiência de fazer corpo com a cidade, um modo de estarcom espaços e de alargar e "gaguejar" o que é fazer-pensar dança. Nesse movimento cartográfico criamos danças em expansão, contagiadas e constituídas pelas forças e intensidades do mundo

Por entendermos que a pesquisa que desenvolvemos está em movimento e transformando-se, as cartografias produzidas tornam-se partilhas possíveis que nos possibilitam ativar a dança como forma de estarcom a cidade. Assim, cartografar não é somente documentar, registrar ou representar as nossas ações, é sobretudo uma experiência em dança através dos movimentos de uma grafia sensível e encarnada.

\section{3: Proposições coletivas como experiência de re- existência nas ocupações da cidade do Rio de Janeiro}

Em 2016, Pelbart, em texto lido no Colégio Fernão Dias Paes de São Paulo, fala que as ocupações nas escolas estaduais paulistas de ensino médio - iniciadas no ano anterior, contra um plano arbitrário de reorganização da rede pública estadual pelo governo Alckmin - são um dos gestos coletivos mais ousados vistos no Brasil recentemente, e que esse movimento "destampou a imaginação política em nosso país". Ele acrescenta dizendo que os estudantes introduziram uma nova "coreografia política" nas representações institucionais com uma dinâmica de proliferação, contágio, frescor, afeto coletivo, operando um corte na continuidade do tempo político e uma inflexão na percepção social e na sensibilidade coletiva na cidade de São Paulo. Pode-se dizer que esse corte e inflexão inspiraram movimentos de ocupação que aconteceram em diversos territórios do nosso país (PELBART, 2016, online).
O interesse do Núcleo pela produção de cartografias do corpo na cidade busca mapear, não extensivamente, mas afetivamente, espaços, territórios e movimentos da cidade que operam essa dissidência da qual Pelbart (2016) fala; que agenciam desejos comuns, que interrompem a lógica da subserviência, apatia e passividade e operam a ativação da autonomia, da organização coletiva, da autogestão e da potência micropolítica vibrátil dos corpos. Essa força nos convocou a acompanhar e a realizar ações artísticas em movimentos de ocupação cariocas.

O Núcleo esteve no Colégio Estadual Amaro Cavalcanti, durante o OcupaAmaro, no Palácio Capanema no OcupaMinC e no prédio do Ministério da Saúde do Rio de Janeiro, no OcupaSUS, realizando proposições artísticas.

09 de maio de 2016

Segunda com os estudantes da OcupaAmaro, com a força e o silêncio que nasce do barulho...

Chegamos ao Colégio Amaro Cavalcanti, ocupado há quase um mês...

Chegamos com os nossos materiais de trabalho: baldes, panos de chão, produtos de limpeza, tecido, ideias, atenção aberta, disponibilidade para o encontro, escuta atenta.

Primeiro fomos levadas para uma "expedição cartográfica" pelo prédio. Encontro com as camadas do espaço. Salas, banheiros, quadras, cozinha, dormitório. Sacada (forte), ponto estratégico de melhor visualização da rua.

Muitos e muitos livros intactos, que os estudantes, até então, nunca tinham tido contato, nem sabiam que existiam. Assim como muitos e muitos quilos de carne estragada no congelador, só descobertos na ocasião da ocupação. Achamos livros de Artes, achamos Lygia Clark e Hélio Oiticica na página 94. Carregamos esses livros conosco, para utilizá-los na nossa atividade. Não que acreditemos na pedagogia da cartilha, mas confiamos que os livros têm o poder de ativar a curiosidade e de abrir mundos.

A movimentação é intensa. Professores da própria escola, jornalistas, pesquisadores, pessoas apoiando com doações, fluxo de estudantes. Número infinitamente menor do que as 2 mil pessoas que circulavam na escola diariamente antes da greve e da ocupação, mas essas que ali estão e permanecem não só circulam... elas cuidam, gerenciam, persistem, insistem, constroem dia-a-dia, minuto a minuto aquele espaço e todas as suas relações. De cara, observamos que não há um líder, não tem ninguém dizendo a todos o que fazer. Pelo menos nessa escala convival da ocupação... (certamente existem lideranças e hierarquias no movimento como um todo). Cada um cuida de algumas coisas, eles vão se revezando em tarefas e isso é muito marcante.

Iniciamos a nossa proposta de limpeza coletiva do espaço no hall de entrada da escola:

Convidamos todo mundo... Alguns chegam, outros desconfiam, as câmeras se voltam pra nós. Molhar, torcer, conectar pés, bacia, costas, braços, cabeça... Tudo meio estranho, tudo meio familiar.

Eles embarcam, nós também. Sentimos todos o peso 
e a insistência dessa ação. Alguns encontram o silêncio que permite se conectar, outros estão dispersos e incomodados. Não tem jeito certo de fazer, tem que descobrir fazendo...

Estendemos, então, o tecido de voile no chão para iniciarmos uma adaptação de "a viagem" de Lygia Clark. Quem quiser deita... um de cada vez. Só quem quiser. Atenção para escutar outras coisas que não as próprias palavras. Eles se interessam, "escutar o quê?" Dar espaço para a escuta do silêncio que é cheio de rua, gaita escocesa, conversa, carro, respiração... É dificil o silêncio em um momento em que se precisa gritar tanto!!!! Falar muito e repetir inúmeras vezes... Mas ele se faz. E depois de o primeiro estudante ser envolvido pelo pano, carregado coletivamente pelo hall e pousar embaixo da escada, trama-se uma rede entre nós. JUNTOS. Começa nesse momento o que achamos que pode ser mais relevante nesse encontro... que é o próprio encontro... (E não em si a realização da atividade proposta, porque não há nada que possamos ensinar fora do encontro. Não há conteúdo mais importante do que a vida)...

As palavras, as percepções, imagens, reflexões encharcadas da vida, do corpo que ocupa, que permanece, que insiste e que resiste.

\section{- Parece um morto.}

- Pode-se velar alguém sem estar morto? O cuidado com o corpo do outro. A morte como assunto, o que estamos matando de um sistema escolar falido para fazer nascer uma nova escola. As pequenas mortes que devem acontecer para o novo poder nascer...

- Como é o nome disso? Dança? Vamos criar um nome pra isso...

\section{- Corpo velado!}

- Como reativar esse estado de escuta no nosso dia-a-dia, como podemos nos escutar melhor?

- Parece que eu deveria acordar assim toda manhã, mas nós já acordamos estressados, com panelaço...

- O que podemos fazer com isso? Um texto... Um caderno... Vamos criar o nosso livro de ocorrências...

Muitas questões iam surgindo cada vez que uma pessoa fazia a experiência, e a cada vez era um novo espaço de atenção e escuta.

Percorremos alguns espaços da escola e encerramos o trabalho no refeitório. Lugar que nos parece crucial para a manutenção da ocupação e das relações. O lugar da comida. Que aliás é onde todos se encontram...

Para Lepecki (2013, p. 56), a política, diferentemente da politicagem dos políticos, seria "uma intervenção no fluxo de movimento da cidade e nas suas representações", realizando uma operação coreográfica de ruptura da fantasia do espaço público como vazio ou livre de acidentes de terreno. Essa intervenção transforma um espaço de circulação compulsória num espaço onde o sujeito possa aparecer não agenciado por "vetores de sujeitificação pré-dados” (LEPECKI, 2013, p. 56).

${ }^{5}$ Este texto é parte de uma cartografia escrita após o encontro com os estudante da Ocupa Amaro. A cartografia na íntegra está disponível em: $<$ www.nucleodeestudoseencontros.blogspot.com. br>.
Nesse contexto, a cidade é mais do que o cenário das lutas sociais contemporâneas, o direito à cidade é o próprio epicentro das disputas em questão. $\mathrm{O}$ direito à realização de novas coreografias na utilização dos bens públicos comuns, às gestões mais participativas e menos arbitrárias, e aos projetos urbanos menos mercadológicos e mais comuns, voltados ao bem-estar dos seus moradores e não aos interesses especulativos do mercado. $\mathrm{O}$ direito à educação pública de qualidade, à cultura e de acesso ao sistema único de saúde, são algumas das lutas em torno da cidade e por condições mais igualitárias de vida.

A greve de ocupação ganha força na medida em que investe os espaços públicos de uma produção afetiva, operando a construção de novos territórios existenciais. Assim, o espaço público não é somente cenário para esses movimentos de ocupação, os movimentos em si produzem ou reproduzem o caráter público do ambiente material.

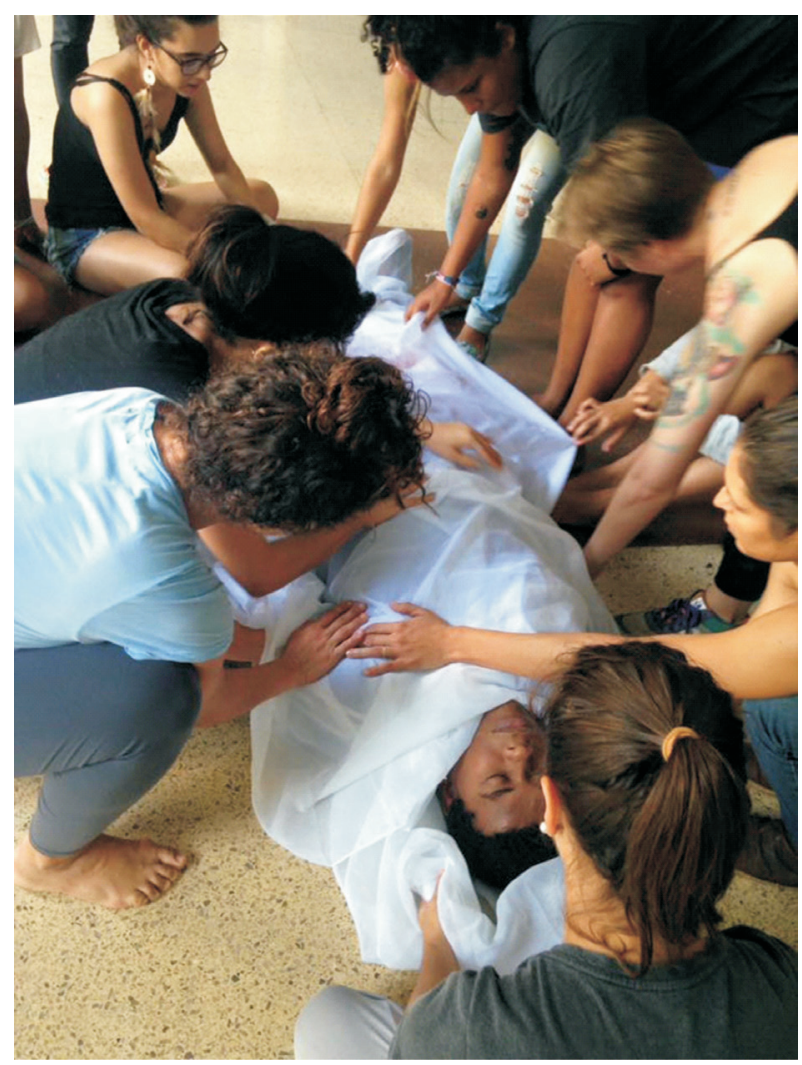

Figura 2 - Proposição no OcupaAmaro

Nas ocupações por nós vivenciadas, percebemos que o espaço público é reinventado, repensado, criado pela presença das pessoas, pelas práticas comuns, encontros e pelo ato de transformar o espaço em lugar e o lugar em casa. Transformar o espaço público em casa, reconfigurar o que é da esfera pública e da esfera privada, cuidar dos prédios públicos como se cuida do próprio lar é também redimensionar a ação política. Os ocupantes estabelecem uma vivência em comum: dormem, comem, conversam, vivem juntos. Cria-se - através do ato de ocupar um espaço, da organização de grupos de trabalho e de uma gestão coletiva, da promoção de debates e programações culturais - uma inventiva

Fractal, Rev. Psicol., v. 29 - n. 2, p. 143-151, 2017 
re-existência às medidas arbitrárias e autoritárias que o País, o Estado e a cidade do Rio de Janeiro vêm sofrendo nos últimos anos e particularmente em $2016 .{ }^{6}$

Como aponta Pelbart (2008), se as formas de resistência ao poder capitalista, há décadas atrás, se pautavam numa matriz dialética de oposição direta ao poder concebido como centro de controle, atualmente, as formas de resistir fazem eclodir posicionamentos híbridos, oblíquos e sempre cambiantes que se constituem num plano coletivo. O coletivo não é reunião de pessoas, mas a força de constituição de um plano comum, um plano de inscrição dos movimentos que convocam a criação de mundos co-possíveis. Deste modo, a resistência opera um desarranjar das configurações dominantes e produz um movimento de contágio e difusão de forças singulares criando um plano comum de re-existência, acolhendo as diferenças e produzindo deslocamentos.

Uma das proposições que nos ajuda a refletir e praticar a dimensão coletiva a partir do encontro é a Limpeza Coletiva do Chão. Conforme Oida (2007) no livro $O$ ator invisivel, alguns coletivos teatrais, práticas religiosas e de artes marciais orientais realizam essa atividade de forma ritualizada. A proposta parte da ação cotidiana de limpar o chão e se interessa mais pelo modo como tal limpeza se dá do que na funcionalidade da ação em si.

Os primeiros direcionamentos são para que cada participante escolha um pano de chão, mergulhe em um balde com água e torça. Neste momento, pede-se atenção ao contato dos pés com o chão, ao alinhamento da bacia em relação a coluna, e a ativação do centro do corpo. Todo o corpo engaja-se na ação de molhar e torcer o pano. Os participantes colocam-se lado a lado, em contato, com as palmas das mãos sobre os panos estendidos no chão, em uma base de quatro apoios: ísquios direcionados para

\footnotetext{
${ }^{6} \mathrm{Em} 2016$ o Brasil viveu um processo de impeachment presidencial que foi entendido por uma parcela da população como golpe de Estado. A presidenta Dilma Rousseff, reeleita em eleições diretas no ano 2014, foi deposta e substituída pelo vice-presidente de sua chapa, Michel Temer. Com o princípio deste novo governo o país passou a sofrer uma série de medidas arbitrárias que vão desde cortes sistemáticos no investimento em áreas fundamentais para o desenvolvimento social - como a educação e a cultura -, até o desmonte dos direitos sociais e humanos - com o aumento significativo da violência policial no exercício de contenção das manifestações populares que se posicionaram contrárias ao sistema de governança pós-impeachment. Afora os comprometimentos à nível federal, no âmbito estadual e municipal, a população do Rio de Janeiro convive com um legado de inadimplência em diversos setores do funcionalismo público, fomentado pelos investimentos feitos nas obras da Copa do Mundo de 2014 e dos Jogos Olímpicos de 2016. Uma gestão de recursos financeiros demasiadamente comprometida com iniciativas de cunho privado que tem precarizado a largos passos a oferta pública de serviços de saúde e educação.
}

cima, topo da cabeça para baixo. As indicações que sucedem orientam o deslocamento de uma extremidade a outro do espaço e apontam para a importância de se realizar esta ação juntos e em silêncio. A duração e a velocidade do deslocamento são criados pelo grupo durante a experiência. Ao atravessar o espaço a escuta se amplia: trabalhamos para manter a conexão entre a estrutura do corpo e a estrutura do espaço; entre o tempo pessoal e o tempo do grupo; a presença do corpo e a poética do espaço. Tal implicação aguça a percepção e a sensibilidade criando uma dimensão coletiva na ação que possibilita vivenciar esse chão tantas vezes pisado, de uma maneira nova. Permite fazer re-existir o espaço cotidiano. 
vas de Clark ativam, pela experiência sensorial do corpo, a dimensão do comum que consideramos tão importante neste contexto de produção de novas cidades possíveis.

Lygia Clark foi uma das fundadoras do movimento neoconcretista no Brasil e juntamente com Hélio Oiticica, Lygia Pape, Ivan Serpa, entre outros artistas, uma das pioneiras a trazer para o campo das artes a experiência de co-participação, afirmando a relação arte-vida e o público como propositor.

Nas experimentações coletivas realizadas durante a estadia de Clark na França e a fase posterior de retorno ao Brasil, denominada Estruturação do Self, a artista vai afinando seu envolvimento com a produção de objetos que não são pensados por seu valor estético, mas em sua potência relacional. Os objetos relacionais ativam a awareness, a presença do corpo, e potencializam experiências transubjetivas ou transicionais; atuam como agentes de uma experiência sensorial coletiva de relação entre o corpo e o mundo. Eles têm assim uma potência poética de colocar o imaginário e a sensopercepção em movimento. Segundo Pedrosa, quando alguém participa de uma experimentação como essas, não participa de uma obra, mas inaugura um corpo-coletivo e cria um espaço-tempo para um "exercício experimental de liberdade" (PEDROSA apud FABIÃO, 2014, p. 287).

Se acompanharmos o pensamento de Lepecki podemos afirmar que Lygia cria com suas proposições uma coreo-grafia espacial afetiva. Lepecki (2014, p. 282) percebe no trabalho da artista uma "geografia afetiva de viver" que cria o que ele denomina de "diagramas para coexistência social". Sua obra se afirma enquanto ato imanente que se desdobra numa ação coletiva que coloca em jogo os limites individuais do corpo. Arte coletiva, por excelência onde o artista-criador não é o centro da experimentação, ele tampouco é criador sozinho, sendo o público co-criador de uma experiência compartilhada. Abre-se um espaço-tempo para uma atmosfera de partilha da experiência sensível e criação de um continuum entre corpo-mundo (LEPECKI, 2014).

No nosso encontro com os estudantes ocupantes do Colégio Amaro Cavalcanti, e em outra ocasião, com os profissionais de saúde da ocupação do Ministério da Saúde, realizamos um trabalho inspirado na proposição "Viagem" de Lygia Clark. Estendemos um tecido de voile no chão, o chão e o material se fizeram espaço para partilha da experiência e o corpo confiou e entregou seu peso. Nós sustentamos juntos o peso de cada um e atravessamos o espaço da ocupação, traçando linhas movediças com nosso corpo-coletivo. O silêncio se fez presença e foi possível escutar as intensidades mudas. Essa experiência conectou e modificou o estado dos corpos, o tônus, eriçou os pelos e gerou uma contração coletiva, abrindo brechas para depoimentos, impressões, assuntos e partilhas que fizeram dançar os limites corpo-objeto/corpo-mundo, redesenhando a coreografia afetiva do espaço e ativando outros modos de re-existência.

\section{Considerações finais}

A experiência de encontro com pessoas e lugares que é facilitada pelas proposições em dança realizadas pelo projeto nos ajuda a entender que as relações entre o corpo e os espaços da cidade não estão previamente determinadas, nem cristalizadas em suas práticas ordinárias. É a qualidade da nossa presença e a relação dos corpos com o mundo que cria este estarcom e que modifica a maneira pela qual nos relacionamos com as pessoas e os lugares. Nos movimentos de ocupação que vivenciamos percebemos que ocupar, insistir, resistir e inventar os espaços públicos pode forçar novas possibilidades de comum, ressignificando os afetos, ajudando a reimaginar o sistema de representação macropolítico, refazendo assim o chão que erode sob nossos pés.

Desta maneira, atualizamos a pergunta feita no início do nosso processo de pesquisa: Como dançar nesses tempos em que o chão está em plena erosão? Como dançar findos 2016? Como manter-nos conectadas com movimentos que ativam a dimensão vibrátil dos corpos e acionem possibilidades de re-existência na cidade? Como permanecer dançando e produzindo movimento de vida em tempos que se mostram movediços? Como seguir produzindo uma dança em ressonância com o mundo?

Estarcom essas perguntas nos parece cada vez mais urgente e as respostas são impermanentes. É necessário estar sempre à espreita, praticando a atenção do cartógrafo para encontrar as brechas e as dobras em que essas potências possam emergir...

\section{Referências}

AgOstinho, M. Pessoas e lugares. Revista Pedras d'Água a arte de estar com pessoas e lugares. Lisboa, 2010. Disponível em: <http://www.c-e-m.org/newsletter/revista_pessoas lugares.pdf $>$. Acesso em: mar. 2016.

BARROS, R.; PASSOS, E. A cartografia como método de pesquisa-intervenção. In: KASTRUP, V.; PASSOS, E.; ESCÓSSIA, L. (Org.). Pistas do método da cartografia: pesquisa-intervenção e produção de subjetividade. Porto alegre: Sulina, 2009. p. 17-31.

DELEUZE, G.; GUATTARI, F. Mil Platôs. 2. ed. São Paulo: Editora 34, 1996. v.1.

FABIÃO, E. The making of a body: Lygia Clark's anthropophagic slobber. In: BUTLER, C. H. (Org.). Lygia Clark: the abandonment of art, 1948-1988. New York: The Museum of Modern Art, 2014. p. 294-299.

GUATTARI, F.; ROLNIK, S. Micropolítica: cartografias do desejo. Petrópolis: Vozes. 1996.

JACQUES, P. Errâncias urbanas: a arte de andar pela cidade. Rio Grande do Sul: UFRGS, 2005. Disponível em: $<$ https://www.ufrgs.br/propar/publicacoes/ARQtextos/PDFs revista_7/7_Paola\%20Berenstein\%20Jacques.pdf>. Acesso em: 13 nov. 2016.

LEPECKI, A. Planos de composição. In: GREINER, C.; SANTO, C. E; SOBRAL, S. (Org.). Cartografia: Rumos Itaú Cultural Dança 2009-2010. São Paulo: Rumos Itaú Cultural, 2012. p. 13-22. 
LEPECKI, A. Coreo-política e coreo-polícia. Ilha Revista de Antropologia, Florianópolis, v. 13, n. 1,2, p. 041-060, jan. 2013. Cross ${ }^{\text {Ref. }}$

LEPECKI, A. Affective geometry, immanent acts: Lygia Clark and performance. In: BUTLER, C. H. (Org.). Lygia Clark: the abandonment of art, 1948-1988. New York: The Museum of Modern Art, 2014. p. 278-293.

NÚCLEO DE PESQUISA, ESTUDOS E ENCONTROS EM DANÇA. Disponível em: <http://nucleodeestudoseencontros. blogspot.com.br>. Acesso em: 16 out. 2016.

OIDA, Y. O ator invisível. São Paulo: Via Lettera, 2007.

PASSOS, E.; KASTRUP, V.; ESCÓSSIA, L. (Org.). Pistas do método da cartografia: pesquisa-intervenção e produção de subjetividade. Porto alegre: Sulina, 2009.

PELBART, P. Elementos para uma cartografia da grupalidade. In: SAADI, F.; GARCIA, S. (Org.). Próximo ato: questões da teatralidade contemporânea. São Paulo: Itaú Cultural, 2008. p. 33-37. Disponível em: <https://desarquivo.org/sites/default/ files/pelbart_peter_elementos.pdf $>$. Acesso em: 13 nov. 2016.

PELBART, P. Por um corpo vivo: cartografias biopolíticas. Cad. saúde Ment, [S.1.], v. 2, n. 1, p. 25-37, 2009. Disponível em: $<$ http://pesquisa.bvs.br/brasil/resource/pt/sus-23953?lang=es>. Acesso em: 16 out. 2016.

PELBART, P. Pelbart: tudo o que muda com os secundaristas. Outraspalavras: comunicação compartilhada e póscapitalismo, São Paulo, 13 maio 2016. Disponível em:__http:// outraspalavras.net/brasil/pelbart-tudo-o-que-muda-com-ossecundaristas/>. Acesso em: 13 nov. 2016.

ROLNIK, S. Cartografia sentimental: transformações contemporâneas do desejo. São Paulo: Estação Liberdade, 1989.

ROLNIK, S. Entrevista: Suely Rolnik. ReDOBRA: Plataforma Corpocidade, n. 8, 18 dez. 2010. Disponível em: <http://www. corpocidade.dan.ufba.br/redobra/r8/trocas-8/entrevista-suelyrolnik/>. Acesso em: 15 jun. 2016.

Recebido em: 22 de novembro de 2016 Aceito em: 9 de junho de 2017 